3. Порушення регламенту технічного обслуговування здатне негативно впливати на Нд ТО. Однак, застосування належного ремонтного обслуговування, з метою відновлення або відновлення ТО, дозволяє підвищити в певних межах їх Нд.

4. За допомогою засобів технічного застосування й технічного обслуговування ТО можна управляти їх Нд

5. На Нд ТО істотний вІлив виявляє рівень технічної культури, шо існуєнп на підшриємстві у тому числі важливої ії складової - технологічної культури

\title{
Jiтература
}

1. Воинова С. А. Воинов А. ІІ. Роль нагрузки в задачах управления надежностью технологических агрегатов // Сб. «Тепловые режимы и охлаждение радиозлектронной аппаратуры». Одесса: НИИ «IIторм», 1994, № 12. - C. $68-73$.

2. Воінова С. О. Можливості підвищення надійності технічних об'єктів з малим залишковим ресурсом. // 36. наук. пр. «Прогресивні техніка та технології харчових виробництв, ресторанного господарства і торгівлі».Харк. держ. ун-т харчування та торгівлі. - 2009. - Вип. I(9). - С. $307-313$.

3. Воінова С. А. Влияние цлительности функционирования технических объектов на их технологическую эффективность // 3б. матер. 5-ої Міжнар. н.-Іракт. конф. "Управління ефективним енерговикористанням“ (4 - 5 вересня 2003 р., Одеса). - Одеса: Вид. ТЕС, 2003.- С. 89 - 90.

4. Воинова С. А. Управление переходными процесами технологических машин при ограничениях на их режимы работы. // Тез. докл. 1-ой націон., науч.-грактич, конф. «Хлебопродукты-94». (14-16 сент. 1994 г.). - Одесса: 1994.

5. Хобін А. А., Воінова С. О. Підвишення надійності технологічного обладнання АПК при заданому рівні безаварійності // Тези допов. Міжнар. наук.-техн. конф. «Розробка та впровадження нових технологій і обладнання у харчову та переробні галузі АПК». - Київ, 19-21 жовтня 1993. - Київ: КТІХП. 1993.

\section{ДИАГНОСТИРОВАНИЕ ДЕРМАТОЛОГИЧЕСКИХ ЗАБОЛЕВАНИЙ ПАЦИЕНТОВ С ПОМОЩЬЮ ИСКУССТВЕННОЙ НЕЙРОННОЙ СЕТИ}

\author{
Высоцкая Е.В., К.Т.Н., доцент, Кириченко Ю.В., \\ Жукова Н.В., врач-дерматолог 2-го городского КВД \\ Харьковский национальный университет радиозлектроники
}

B cтатье были рассиотрены вопросы создания нейронной сети, позволяюицей определять дерматологические заболевания по клинико-биохимическии показателяи паииентов с учетои кооперативного взаимодействии интегративных систел контроля гомеостаза - эндокринной, нервной и иммунной и принципа системно-антисистемного взаимодействия.

The article examined the creation of a neural network, which allows to determine the dermatological diseases on the clinical and biochemical parameters of patients in the light of the cooperative interaction of integrative control systems of homeostasis - the endocrine, nervous and immune system-and the principle of anti-system interaction.

Ключевые слова: искусственная нейронная сеть, классификация, клинико-биохимические показатели, дерматозы.

Кожа является сложным органом, который играет важную роль в жизнедеятельности организма. IІричины возникновения кожных заболеваний разнообразны и сложны. Кожа постоянно подвергается воздействию химических соединений окружающей среды, различных грибков, вирусов, бактерий, что приводит к метаболическим изменениям в составе кожи. Все кожные заболевания сопровождаются определенными вторичными манифестными признаками и симптомами: сыпью, зудом и др.

Важной медико-социальной проблемой является широкая распространенность различных дерматозов, особенно в индустриально развитых странах, что сопровождается формированием тяжелых, резистентных к лечению, инвалидизирующих форм заболевания у значительного числа пациентов.

Хронические папулезные и зудящие дерматозы - группа наиболее распространенных и недостаточно изученных дерматозов, имеющих хроническое рецидивирующее течение, полиморфность клинической симптоматики, связанной с системными нарушениями различных физиологических функций организма. Проблема этиологии, патогенеза и рационального лечения этой патологии остается весьма актуальной в современной дерматологи.

В настоящее время псориаз является одним из самых распространенных хронических дерматозов, который встречается примерно у 1-3\% населения планеты, что составляет до $12-15 \%$ всех дерматозов. Отмечается постоянный рост больных экземой, что составляет $30-40 \%$ всех кожных заболеваний. Акне поражает около 80 
\% лиц от 12 до 25 лет и примерно 30 - $40 \%$ лиц старше 25 лет, являясь основным в ряду заболеваний, вызывающих стойкий психический и физический дискомфорт.

Современная дерматология сделала значительный рывок вшеред. Появились современные методы диагностики и лечения, которые пюзволяют определить причину возникновения заболевания и подобрать подходяшее лечение. Но, несмотря на обширные исследования в области математических методов диагностики, диагностические программы еше недостаточно совершенны. Это является одной из иричин их крайне редкого использования в больницах и поликлиниках. Для создания более совершенных программ необходимо развивать методы интеллектуальног анализа данных для диагностики дерматологических заболеваний.

К методам интеллектуального анализа данных, применимых к задачам диагностики, в настоящее время относят: статистические, логико-статистические методы многофакторного моделирования и кибернетические методы оптимизации [1].

К статистическим методам диагностирования относят регрессионный анализ, дискриминантный анализ, факторный анализ и т.п. Результаты применения статистических методов достоверны лишь с определенной вероятностью, задаваемой исследователями перед началом обработки статистических данных. Очевидно, что вывод диагностической программы должен быть однозначным. Также существенный недостаток состоит в том, что статистический «вес» каждого показателя в огромной степени зависит от характеристик обучающей выборки. Недостатком логико-статистического метода является невозможность посгроения алгоритмов, распознаюцих болыное количество объектов.

Алгоритмический метод позволяет врачу прослеживать логику постановки диагноза на всех этапах работы. Но определенные ограничения обусловлены тем, что алгоритм и база данных представляют собой единое целое. Любые изменения в работе алгоритма влекут за собой коренное изменение структуры самого алгоритма и элементов информационного содержания. При этом трудно заранее предиолагать, каким образом изменится результат диагностической процедуры. В алгоритмах с жесткой схемой существует риск игнорирования редких, но важных показателей

Человеку-эксперту оценить влияние изменения этих показателей на постановку диагноза очень сложно. Тем не менее, нейронные сети оказались способными помочь принять решение, основываясь на выявлясмых ими скрытых закономерностях в многомерных данных. Отличительное свойство нейронных сетей состоит в том, что они не программируются - не используют никаких правил вывода для поостановки диагноза, а обучаются делать это на примерах.

ІІреимушества систем, построенных на нейронных сетях перед человеком-экспертом: $у$ них нет предубежлений и они устойчивы к различным помехам; они не делают поспешных выводов; эти системы выдают не первое нашедшееся, а оптимальное (по определенным критериям) решение; база знаний может быть очень и очень большой. Введенные в машину один раз, знания сохраняются навсегда. Человек же имеет ограниченную базу знаний, и если данные долгое время не используются, то они забываются и навсегда теряются.

Целью данной работы является исследование и создание нейронной сети, позволяющей эффективно распознавать клинико-лабораторную характеристику дерматологических заболеваний для раннего обнаружения различных дерматозов.

Формальная задача диаг ностики дерматологического заболевания сводится к определению наличия (с заданной вероятностью) некоторых заболеваний (псориаз, экзема, крапивница) у человека по нешолным лабораторным анализам, используя искусственные нейронные сети. С математической точки зрения требуется установить следующую зависимость

$$
\begin{aligned}
& y_{1}=f\left(x_{1}, x_{2}, \ldots, x_{54}\right) ; \\
& y_{i}=f\left(x_{1}, x_{2}, \ldots, x_{54}\right) ; \\
& y_{k}=f\left(x_{1}, x_{2}, \ldots, x_{54}\right) ; \\
& y_{k+1}=f\left(x_{1}, x_{2} \ldots, x_{54}\right) ;
\end{aligned}
$$

где $v_{i}$-вероятность наличия і-го дерматологического заболевания, $i=\overline{1, k} ; k=14$;

$v_{k+1}$ - вероятность отсутствия данных заболеваний;

$r_{1} r_{54}-6$ иохимические и клинические анализы крови и мочи.

Рассмотрены показатели белкового (ast, alt, urea и т.д.), углеводного (gluc, Mg, Г-6ФФГ и т.д.), микроэлементного (Fe, Сa, Mg и т.Д.) и жирового (ИБХЈ, МДА, Циены и т.д.) обменов. Все показатели были классифицированы по влиянию на органы: печень (prot, alb, индикан и т.II.), почки (ggt, alp и т.II.), сердце (crea, КФК и т.п.) и отношению к системам организма: ферментативная (ggt, alp, СДГ, ЈДГ и т.п.), антиоксидантная (chol и т.п.), оксидантная (2,4ДНФ-А, Fe и т.п.), гормональная (кортизол, пролактин и т.п.), нервная (ГАМК, таурин и т.п.), иммунная (IgA, IgM, CD-2, CD-4, CD-8, CD-19, Ил и т.п.).

Было рассмотрено 54 различных показателя, которые были взяты у 332 пациентов с различными кожными заболеваниями (рассмотрено 14 вариантов дерматозов: псориаз, экзема, крапивница и т.д.) и 147 человек контрольной группы. Всего обработано 7510 значений показателей. 
В результате статистического анализа данных в системе SPSS 12.0, было установлено, что ряды данных для всех показателей не являются нормально распределенными, поэтому ограничено применение группы методов для нормально распределенных величин. К тому же было установлено, что система является нелинейной. ІІоэтому применение нейронной сети в данном случае огравдано.

ІІоставленная задача является задачей классификации, поэтому было принято решение использовать полносвязную многослойную нейронную сеть. Топология этого вида искусственной нейронной сети предполагает, что ИНС сама установит нужные весовые коэффициенты для всех связей в ходе обучения. Число входных и выходных элементов определяется числом входных параметров и числом известных классов [2, 3, 4].

Суцествует множество процедур и методов для выбора количества нейронов и количества слоев в сети, как правило, они чисто эмпирические и определяется степенью обучаемости нейронной сети. В данной работе было принято решение для подбора конфигурации использовать классический метод перебора. Количество входных и выходных слоев ограничено данной задачей количеством показателей и числом возможных диагнозов соответственно. Таким образом, $N_{\varepsilon}=54, N_{\text {sh }}=14$. I Іостроим для начала нейронную сеть с одним скрытым слоем. Далее их количество может наращиваться в процессе обучения сети по мере необходимости. Количество нейронов в скрытом слюе будем Іодбирать начиная с грех.

Для обучения ИНС будем использовать классически метод обратного распространения ошибки, который реализован с помоцью градиентного алгоритма наискорейшего спуска. Поскольку данная методика имеет линейную скорость сходимости, а также резкое замедление процесса в окрестности точки оптимального решения, а функционал ошибки является многоэкстремальной функцией, то применяющийся в большинстве случаев случайный выбор начальных значений весовых коэффициентов нейронной сети приводит к тому, что метод обратного распространения ошибки может становиться в локальном минимуме, не обеспечив необходимой точности прогноза.

Целесообразно начальные значения весовых коэффициентов задавать близкими к координатам экстремума выхода нейрона [5]. Наибольшую эффективность показал прием выбора в качестве начальных значений координат центров масс линейно разделимых областей нейронов, соответствующих уровню логической единицы на выходе нейросети:

$$
w_{i}=\frac{1}{m} \sum_{i=1}^{m} x_{i j}
$$

где $x_{i j}$ - значение $i$-го входа $j$-го элемента выборки, $m$ - количество выборок обучающей последовательности.

Для алгоритма обратного распространения ошибки функция должна быть непрерывной, дифференцируемой и монотонной. Всем этим требованиям удовлетворяет функция Гаусса:

$$
y(x)=\exp \left(\frac{-(x-m)^{2}}{2 \cdot \sigma^{2}}\right)
$$

Ее график показан на рисунке 1 .

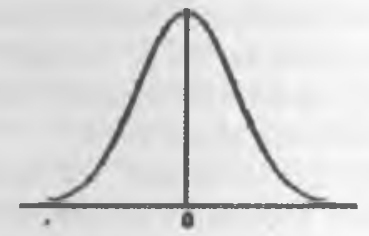

Рис. 1 - График функции Гаусса $[0,1]$.

Цля правильного обучения нейронной сети все входные данные нормализовали, т.е. привели их к интервалу

$$
x_{\text {Hop }}=\frac{x-x_{\min }}{x_{\max }-x_{\min }}
$$

Выходные данные для обучения нейронной сети приняли значения “ 0 ” на всех выходах, кроме одного, который соответствовал конкретному заболеванию. Например, для диагноза экзема, массив, который подавали на выход нейронной сети, выглядел так: $Y_{в ы x ~}=\{0,0,1,0,0,0,0,0,0,0,0,0,0,0\}$

IІосле нормализации последовательно провели обучение различных архитектур нейронных сетей с одним скрытым слоем. Для этого использовали данные клинико-биохимических показателей 100 пациентов. Оставшиеся значения показателей 47 пациентов использовали для тестирования обученной сети.

Диаграмма ошибки обучения в зависимости от количества нейронов в скрытом слое представлена на рисунке 2.

Из графика можно сделать вывод, что наименьшая ошибка обучения была при 20 нейронах в скрытом слое 


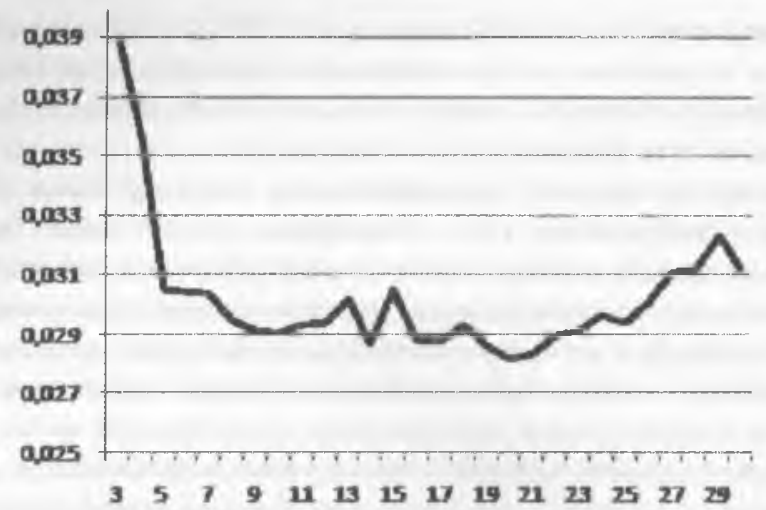

Рис. 2 - Диаграмма ошиб́ки обучения в зависимости от количества нейронов в скрытом слое

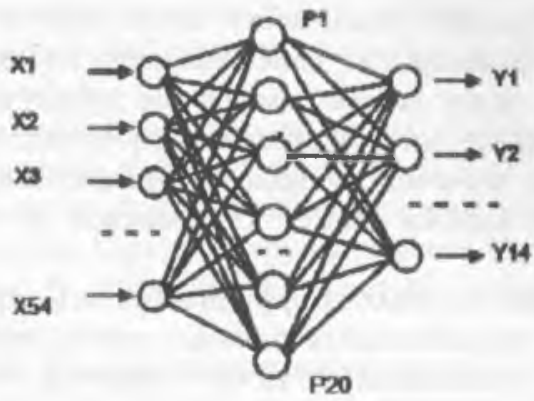

Рис. 3 - Оптимальная архитектура нейронной сети

Следовательно, сеть с одним скрытым слоем и архитектурой [54-20-14], выбрали в качестве огтимальной нейронной сети, которая способна решать задачу классификации дерматозов по клинико-биохимическим показателям.

Анализ полученных данных показал, что у 130 больных псориазом диагноз был определен безошибочно и у 6 из 203 пациентов, страдающих другими формами дерматозов, был определен ошибочный диагноз. Таким образом, применение предложенной нейронюй сети позволило корректно классифицировать $97 \%$ всех больных дерматозами.

Выводы

В данной статье проблема диагностики дерматологических заболеваний организма человека рассматривается в кооперативном взаимодействии интегративных систем контроля гомеостаза - эндокринной, нервной и иммунной и принципа системно-антисистемного взаимодействия.

В результате проведенного исследования была создана нейронная сеть, позволяющая по клиникобиохимическим показателям определять дерматологические заболевания, которая является классифицирующей системой для раннего обнаружения различных дерматозов

Данная нейронная сеть пригодна для создания системы диагностики, которая позволит проводить комплексную, неинвазивную диагностику состояния организма пациента на клинико-биохимическом уровне, а также повысить качество диагностики за счет автоматизации процесса получения диагноза.

\section{Литература}

1. Реброва, О.Ю. Применение методов интеллектуального анализа данных для решения задачи медицинской диагностики / О.Ю. Реброва // Новости искусственного интеллекта. - 2004. - №3. - С.7680.

2. Богославский, С.Н. Область применения искусственных нейронных сетей и перспек] ивы их развития С.Н. Богославский // Научный журнал КубГАУ.-2007.-№27(3)-С. 12-16;

3. Ежов, А. Нейронные сети в медицине / А.Ежов, В.Чечеткин // Открытые системы. 1997.-oㅡ -С $34-37$.

4. Москвич, Д.Н. Синтез нейронных сетей при их практическом применении / Д.Н. Москвич // Вестник СевКавГТУ (Серия «Физико-химическая»). 2004.-№1(8).-С.6-7.

5. Столяренко, М.А. Проблемы сходимости обучения искусственных нейронных сетей / М.А. Столяренко // Вестник Национального технического университета "ХПИ".-Харьков: НТУ „ХПИ”, 2008.-№12.-С.810. 